\title{
Unusual Biliary Complication following Christmas Eve Dinner
}

\author{
Lumir Kunovsky $^{a, b}$ Pavla Tesarikova ${ }^{c}$ Amrita Sethi $^{d}$ Radek Kroupa $^{a}$ \\ Milan Dastych $^{\mathrm{a}}$ Jiri Dolina ${ }^{\mathrm{a}}$ Zdenek Kala $^{\mathrm{b}}$ Jan Trna ${ }^{\mathrm{a}, \mathrm{c}}$ \\ aDepartment of Gastroenterology and Internal Medicine, University Hospital Brno, Faculty of Medicine, \\ Masaryk University, Brno, Czech Republic; 'bepartment of Surgery, University Hospital Brno, Faculty of \\ Medicine, Masaryk University, Brno, Czech Republic; 'Department of Internal Medicine, Hospital Boskovice, \\ Boskovice, Czech Republic; ${ }^{d}$ Division of Digestive and Liver Diseases, Columbia University Medical Center, \\ New York, NY, USA
}

\section{Keywords}

Foreign body · Fish bone · Endoscopy · Papilla of Vater ·

Common bile duct · Biliary complications

\begin{abstract}
We present a case of a fish bone impacted in the papilla of Vater resulting in dyspepsia and mild elevation in liver function tests, which was subsequently treated endoscopically. Fish bones are one of the most commonly encountered swallowed foreign bodies. However, involvement of the biliary tract, such as the one described by us, represents an extremely rare complication of fish bone ingestion. The diagnosis of a foreign body in the biliary tract can be difficult, and early endoscopic or surgical extraction may be required to avoid complications such as biliary stone formation, obstructive jaundice, cholangitis or cholecystitis, and/or biliary sepsis. Prompt endoscopic treatment can avoid severe biliary complications or surgical therapy. @ 2021 The Author(s)

Published by S. Karger AG, Basel
\end{abstract}

\section{Introduction}

Foreign body ingestion and food impaction are common occurrences. The majority of ingested foreign bodies will pass through the system spontaneously without any major complications [1]. However, occasionally, endoscopic or surgical intervention is needed $[2,3]$.

Carp is served as a traditional Christmas Eve dinner in the Czech Republic. We present a case of a woman who unintentionally swallowed a fish bone during this holiday dinner that became impacted at the papilla of Vater. Clinically, this resulted in dyspepsia and a mild elevation in liver function tests (LFTs). Early endoscopic intervention prevented serious complications and the need for possible surgery.

Fish bone is one of the most commonly encountered swallowed foreign bodies [3]. Nevertheless, a complication of fish bone impacted in the papilla of Vater is extremely rare.

\section{Case Report}

We present a patient with a previous history of cholelithiasis and choledocholithiasis requiring cholecystectomy and multiple ERCPs with sphincterotomy. One year after the last ERCP, at the age of 79 years, the patient was referred to our hospital for abdominal pain. She presented with postprandial right upper quadrant abdominal pain associated with nausea that persisted for 30 minutes. The symptoms began after a Christmas Eve dinner that included carp. Her past medical history included atrial fibrillation, arterial hypertension, thyroiditis, gastroesophageal reflux, chronic gastritis, diverticulosis, osteoporosis, and surgically treated breast cancer. karger@karger.com www.karger.com/ddi

Karger $\stackrel{\text { ' }}{=}$

BOPEN ACCESS
C 2021 The Author(s)

Published by S. Karger AG, Basel

This is an Open Access article licensed under the Creative Commons Attribution-NonCommercial-4.0 International License (CC BY-NC) (http://www.karger.com/Services/OpenAccessLicense), applicable to the online version of the article only. Usage and distribution for commercial purposes requires written permission.
Correspondence to:

Lumir Kunovsky, lumir.kunovsky@gmail.com 



Fig. 1. a Endoscopic findings: fish bone lodged in the papilla of Vater. b Endoscopic findings: fish bone lodged in the papilla of Vater.

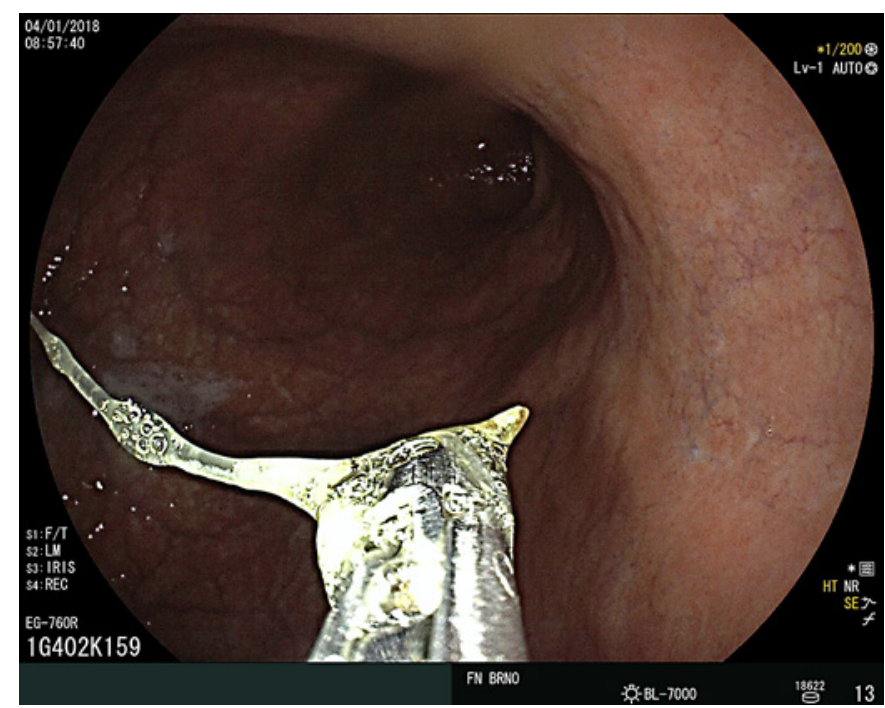

Fig. 2. Fish bone held by grasping forceps during the extraction in the stomach.

Evaluation revealed a mild elevation in AST $(0.63 \mu \mathrm{kat} / \mathrm{L}$; reference range $\leq 0.6 \mu \mathrm{kat} / \mathrm{L})$ and bilirubin $(22 \mu \mathrm{mol} / \mathrm{L}$; reference range $\leq 21 \mu \mathrm{mol} / \mathrm{L}$ ), while other LFTs remained within normal limits. An abdominal X-ray was taken with normal findings, and an ultrasound revealed a $9-\mathrm{mm}$ common bile duct (CBD) without clear evidence of a biliary stone (a 9-mm CBD was taken as being a normal width after cholecystectomy). In performing our differential diagnostics, we also considered a gastroduodenal ulcer or gastritis. An esophagogastroduodenoscopy showed a fish bone lodged in the papilla of Vater (Fig. 1a, b). The bone was gently extracted with grasping forceps (Fig. 2, 3). The patient's dyspepsia resolved, and LFT normalized following removal of the

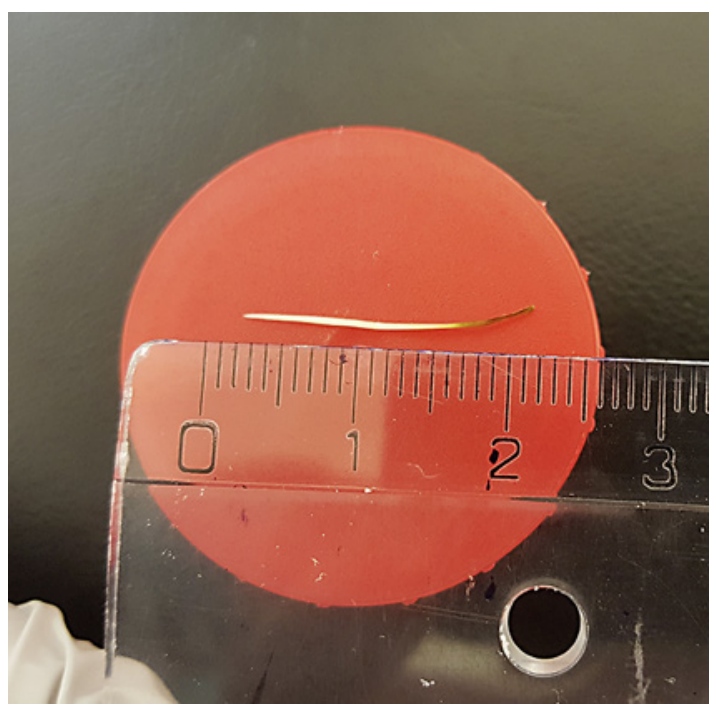

Fig. 3. Extracted fish bone with ruler (centimeters).

fish bone. Because of the absence of cholangitis, antibiotic therapy was not administered. The patient's course was uneventful after the endoscopy.

\section{Discussion}

Accidental foreign body ingestion remains a common clinical problem. Among the many foreign bodies swallowed, fish bone is one of the most commonly encoun- 
tered [1]. Accidental foreign body ingestion may not be noticed by the patient, and the onset of symptoms may be delayed by months or even years, which further complicates the diagnostic process [4]. Fish bones can be difficult to diagnose on X-ray, with a sensitivity of only $32 \%$. Alternatively, CT scans have sensitivities of $90-100 \%$ and specificities of $93.7-100 \%$ and are significantly superior to X-rays. CT not only provides better anatomical information but can also detect other complications such as abscess formation, mediastinitis, and aortic/tracheal fistulas [5]. The majority of cases of swallowed fish bones are asymptomatic, however, some have potential to cause a variety of delayed complications including perforation. The upper esophagus is the site of the highest risk of foreign body impaction and subsequent perforation [5]. Additional locations that are at high risk for perforation occur at points of narrowing or angulation in the gastrointestinal tract, such as the cricopharyngeal ring, aortic arch, lower esophageal sphincter, pylorus, duodenal curve, ligament of Treitz, ileocecal valve, appendix, and the rectosigmoid junction [6].

Fish bones may on rare occasions extend outside the gastrointestinal tract and migrate to surrounding organs, which can result in bizarre manifestations and clinical symptoms. These can include pancreatic granulomas, imitating a tumor of the pancreas [7], hepatic abscess [4], appendicitis [8], or diverticulitis [4]. Involvement of the biliary tract, such as the one described in this case, represents an extremely rare complication of foreign body ingestion [9]. Most of the reported cases of a foreign body in bile ducts are surgical remnants such as sutures, surgical clips, and stents. There are also a few reports of worms, ingested metal pins, tomato skin, shrapnel splinters, toothpicks, chicken bones, and fish bones found in the CBD $[10,11]$. Some of the fish bones were believed to have entered the CBD in an ascending fashion through the papilla, whereas others had evidence of penetration through the walls of the duodenum and the CBD [10]. Foreign bodies can predispose the biliary tree to biliary stones or stricture formation, causing obstructive jaundice or leading to cholangitis or cholecystitis [9].

Overall, 10-20\% of cases of foreign body ingestion require endoscopic removal and less than $1 \%$ need surgical intervention [5]. Concerning biliary foreign bodies, endoscopic or surgical extraction is required to avoid the complications of obstructive jaundice, especially cholangitis and biliary sepsis [12].

In our case, the fish bone became lodged in the papilla (not penetrating through the CBD wall) most likely because of the widened sphincter of Oddi after papil- losphincterotomy, in conjunction with the elongated shape of the bone. Early onset of symptoms enabled rapid diagnostic testing, and early endoscopic intervention prevented serious complications as well as the need for surgery. As the bone protruded from the papilla, it was visible during gastroscopy and could be extracted immediately using a grasping forceps. The patient was thus spared ERCP, which is currently the treatment of choice when a clinical manifestation of biliary tract foreign bodies is present [13].

\section{Conclusion}

Fish bone ingestion is a common problem yet still very challenging to diagnose both clinically and radiologically. In case of any involvement of the biliary tree, early treatment is necessary to prevent complications such as biliary stones or stricture formation, causing obstructive jaundice or leading to cholangitis or cholecystitis. We present an unusual case presenting with biliary symptoms caused by a fish bone lodged in the papilla and avoided serious biliary complications thanks to prompt endoscopic treatment.

\section{Statement of Ethics}

This paper was conducted ethically in accordance with the Declaration of Helsinki. Written informed consent was obtained.

\section{Conflict of Interest Statement}

All authors declare no conflicts of interest in relation to this article.

\section{Funding Sources}

Supported by Ministry of Health of the Czech Republic - conceptual development of research organization (FNBr, 65269705).

\section{Author Contributions}

L.K.: performing endoscopy, writing manuscript, and literature search. P.T.: writing manuscript and literature search. A.S.: contributed in reviewing and editing the manuscript. R.K., M.D., J.D., and Z.K.: critical review of the manuscript. J.T.: contributed in reviewing and editing the manuscript. 


\section{References}

1 ASGE Standards of Practice Committee; Ikenberry SO, Ikenberry SO, Jue TL, Anderson MA, Appalaneni V, Banerjee S, et al. Management of ingested foreign bodies and food impactions. Gastrointest Endosc. 2011 Jun;73(6):1085-91.

2 Weiland ST, Schurr MJ. Conservative management of ingested foreign bodies. J Gastrointest Surg. 2002 May-Jun;6(3):496-500.

3 Ngan JH, Fok PJ, Lai EC, Branicki FJ, Wong J. A prospective study on fish bone ingestion. Experience of 358 patients. Ann Surg. 1990; 211(4):459-62.

4 Bathla G, Teo LL, Dhanda S. Pictorial essay: complications of a swallowed fish bone. Indian J Radiol Imaging. 2011;21(1):63-8.

5 Birk M, Bauerfeind P, Deprez PH, Häfner M, Hartmann D, Hassan C, et al. Removal of foreign bodies in the upper gastrointestinal tract in adults: European Society of Gastrointestinal Endoscopy (ESGE) Clinical Guideline. Endoscopy. 2016 May;48(5):489-96.
$6 \mathrm{Wu}$ C, Hungness ES. Laparoscopic removal of a pancreatic foreign body. JSLS. 2006;10(4): 541-3.

7 Wang WG, Zhang Y, Wang L, Chen Y, Tian BL. Chronic pancreatic inflammatory granuloma caused by foreign body presenting as a pancreatic pseudotumor: a case report and literature review. Pancreatology. 2015;15(5): 573-5.

8 Beh JC, Uppaluri AS, Koh BF, Cheow PC. Fishbone perforated appendicitis. J Radiol Case Rep. 2016;10(7):14-22.

9 Matsubayashi H, Sawai H, Tanaka M, Hotta $\mathrm{K}$, Ono H. Endoscopic removal of foreign body from hepatic duct using wire guided forceps and basket. J Interv Gastroenterol. 2012; 2(2):86-7.
10 Hussain Z, Malik SM, Rasool A, Mattoo S. Rare causes of foreign body in CBD: a retrospective study. JK Sci. 2015;17:209-11.

11 Brunaldi VO, Brunaldi MO, Masagao R, Silva C, Masuda H, Brunaldi JE. Toothpick inside the common bile duct: a case report and literature review. Case Rep Med. 2017;2017: 5846290.

12 Giestas S, Mendes S, Gomes D, Sofia C. Obstructive jaundice due to foreign body in the bile duct: an unusual finding. GE Port J Gastroenterol. 2016;23(4):228-30.

13 Yu M, Huang B, Lin Y, Nie Y, Zhou Z, Liu S, et al. Acute obstructive cholangitis due to fishbone in the common bile duct: a case report and review of the literature. BMC Gastroenterol. 2019;19(1):177. 